\title{
La filosofía griega
}

Héctor Samour

Docente investigador

Universidad Centroamericana José Simeón Cañas, UCA

hsamour@uca.edu.sv

DOI: http://dx.doi.org/10.5377/koot.v0i8.5867

URI: http://hdl.handle.net/11298/382

\section{Resumen}

Se hace una aproximación a la filosofía griega destacando que dicha filosofía surge en un período privilegiado de la historia occidental que ha tenido una influencia enorme en nuestra manera de pensar en la actualidad. La casi totalidad de los conceptos que forman el acervo de la filosofía occidental estuvieron de una u otra forma pensados por los griegos. Se finaliza destacando las vinculaciones entre el pensamiento mítico y el pensamiento racional, mostrando las condiciones que hicieron posible la emergencia de ese peculiar tipo de discurso filosófico que inauguraron los griegos.

Palabras clave: Historia, filosofía, identidad, cultura, antigüedad.

\begin{abstract}
An approach to the Greek philosophy is made by emphasizing that such arises in a fortunate period of the western history that has had a huge influence in our way of thinking nowadays. Almost all the concepts that make up the legacy of the western philosophy were in one way or another assumed by the Greeks. In sum, the following article it is displayed the emphasis of the associations between mythic thinking and rational thought by showing the conditions that made possible the emergence of that peculiar type of philosophical discourse that the Greeks introduced.
\end{abstract}

Keywords: History, philosophy, identity, culture, antiquity.

\section{Importancia de la filosofía griega}

En este artículo haré una aproximación a los aspectos principales de ese período privilegiado de la historia de la filosofía occidental, que es la filosofía griega. Es "privilegiado" porque nuestra manera de pensar, nuestra Weltanschauung, está en gran medida, condicionada e influida por el modo de pensar de los griegos antiguos. Algunas de sus producciones, generalmente científico-técnicas, han sido superadas y 
perfeccionadas por la modernidad, pero otras han sido sólo perfeccionadas y, algunas, ni superadas ni perfeccionadas. Los tiempos posteriores, por ejemplo, en arte, se miran continuamente, en múltiples resurgimientos o renacimientos, en el espejo del tiempo de los griegos. Pero hay más.

La filosofía actual, a veces, busca justificación y legitimación. Y en muchos casos, para definir cuál es la esencia de la filosofía se ha abocado a los griegos para mostrarla en su gestación (Zubiri, Heidegger, Nietzche, Marx, Hegel). Los griegos generaron una forma de pensar y un lenguaje de los que somos deudores, unos conceptos, en fin, que son, en gran medida, nuestros conceptos. O como dice Zubiri: "Es que el pensamiento griego pertenece al pensamiento occidental de una manera mucho más honda que por haber sido el punto de arranque de unas especulaciones que han durado a lo largo de los siglos; Grecia pertenece a nosotros de una manera más fundamental: porque constituye permanentemente y todavía hoy la posibilidad misma de la filosofía occidental". ${ }^{1}$

Ciertamente los griegos pasaron, ya no están. Y en este sentido, Grecia pertenece al pasado que ya no es. Pero donde hay continuidad histórica, lo que desaparece no cae en el vacío, sino que, al desaparecer, deja a las subsiguientes generaciones en una situación definida por las posibilidades que le ha legado aquello que ya no existe, y son estas posibilidades legadas a la posteridad las que constituyen y definen la situación de los sucesores. En este sentido, Grecia pertenece a las posibilidades internas de la filosofía occidental. Pero esta dialéctica de las posibilidades no consiste en una mera recepción. Uno puede pensar que se trata de una mera continuación: Anaximandro, Parménides, Platón, Aristóteles, etc., han tratado una serie de temas, y de esos temas se va a continuar hablando dentro del mundo occidental. Esto es, en parte, verdad, pero no es lo fundamental, porque a lo más conduciría a una especie de cóctel del pasado y del presente. Las ideas del mundo griego, el elenco de conceptos que el mundo griego nos ha otorgado como posibilidades intelectuales, se va a utilizar para resolver problemas completamente ajenos a la mente griega.

La casi totalidad de los conceptos que forman el acervo de la filosofía occidental estuvieron de una u otra forma pensados por los griegos. Hay excepciones, por ejemplo, el mundo griego jamás tuvo ni el vocablo ni la noción de persona, o un concepto o vocablo que respondiera a lo que nosotros entendemos por existencia, que apareció hasta el siglo IV.

Mostraré la evolución de la filosofía griega, insistiendo en los conceptos que tal filosofía dio a luz, y que han tenido una gran repercusión en la historia de la filosofía. Conceptos como logos, aletehia, sophos, eón, einai, physis, nous, epistéme, doxa, dynamis, energeia, eidos, eicasía, eudemonía, pistis, dianoia, ousía, polis, arjé, paideia, telos, entelequia, etc.

${ }^{1}$ Cfr. X. Zubiri, Los problemas fundamentales de la metafísica occidental, Alianza Editorial, Madrid, 1994, pp. 14. 


\section{Surgimiento de la filosofía griega}

La filosofía griega es un proceso evolutivo en el que la filosofía nace arrancándose paulatinamente del mito, se constituye y se desarrolla. Pero no se trata sólo de un proceso meramente lógico o una mera evolución de puras ideas, sino un proceso que surge de las relaciones del ser humano con la naturaleza y la sociedad. Se trata de un proceso histórico sociocultural.

Erróneamente se ha creído que en un momento dado del proceso histórico surge espontáneamente un interés en la pura contemplación desinteresada y racional. Pero esto no es así. Veamos lo que dice Aristóteles al respecto:

"Que no se trata de una ciencia productiva, es evidente ya por los que primero filosofaron. Pues los hombres comienzan y comenzaron siempre a filosofar movidos por la admiración; al principio, admirados ante los fenómenos sorprendentes más comunes, luego, avanzando poco a poco y planteándose problemas mayores, como los cambios de la luna y los relativos al sol y a las estrellas y a la generación del universo. Pero el que se plantea un problema o se admira, reconoce su ignorancia. Por eso también el que ama los mitos es en cierto modo filósofo; pues el mito se compone de elementos maravillosos".

"De suerte que, si filosofaron para huir de la ignorancia, es claro que buscaban el saber en vista del conocimiento, y no por alguna utilidad. Y así lo atestigua lo ocurrido. Pues esa disciplina comenzó a buscarse cuando ya existian casi todas las cosas necesarias y las relativas al descanso y al ornato de la vida. Es, pues, evidente que no la buscamos por ninguna otra utilidad, sino que, así como llamamos hombre libre al que es para sí mismo y no para otro, así consideramos a ésta como la única ciencia libre, pues ésta es sola para sí misma”.

"Y, entre las ciencias, pensamos que es más sabiduría la que se elige por sí misma y por saber, que la que se busca a causa de sus resultados, y que la destinada a mandar es más sabiduría que la subordinada". ${ }^{2}$

¿Se hace ciencia sólo por saber? Aristóteles dice que la sabiduría (la filosofía) es una ciencia contemplativa, desinteresada, no productiva. Pero también dice que la filosofía comenzó cuando ya estaban solucionadas las cuestiones productivas y de "ornato de la vida", con lo cual reconoce la importancia de las condiciones materiales para que surja lo espiritual; sólo cuando existe lo primero se puede dar lo segundo.

${ }^{2}$ Aristóteles, Metafísica, A, 982b, 20/28; 14/6. Las cursivas son mías. 
Sin embargo, Aristóteles olvida algunas cosas, sobre todo, la importancia y decisiva influencia que los modos de inserción de los filósofos en la sociedad ejercen en su filosofía. En este sentido, Zubiri afirma lo siguiente:

"Toda filosofía tiene su base, como supuesto suyo, una cierta experiencia. Contra lo que el idealismo absoluto ha pretendido, la filosofía no nace de sí misma. Y ello, en varios sentidos: primeramente, porque si así fuera, no sería explicable que la filosofía no hubiera existido plena y formal en todos los ángulos del planeta, desde que la humanidad existe; en segundo lugar, porque la filosofía muestra un elenco variable de problemas y de conceptos; finalmente, y sobre todo, porque la posición misma de la filosofía dentro del espíritu humano ha sufrido sensibles oscilaciones...Pero el que toda filosofía parta de una experiencia no significa que esté encerrada en ella, es decir que sea una teoría de dicha experiencia... La filosofía puede contradecir y anular la experiencia que le sirve de base, inclusive desentenderse de ella y hasta anticipar formas nuevas de experiencia. Pero ninguno de estos actos sería posible sino poniendo el pie en una experiencia básica que permitiera el brinco intelectual de la filosofía. Esto quiere decir que una filosofía sólo adquiere fisonomía exacta referida a su experiencia básica... Experiencia significa algo adquirido en el transcurso real y efectivo de la vida. No es un conjunto de pensamientos que el intelecto forja, con verdad o sin ella, sino el haber que el espíritu cobra en su comercio efectivo con las cosas". 3

Anaximandro, por ejemplo, nunca hubiera concebido su sistema cosmológico sin la influencia de las técnicas, y no hubiera sido el poema de Parménides como fue si él no hubiera sido un legislador y hubiese vivido en una ciudad organizada social y políticamente de otra forma a como lo estaba Elea. Y se puede multiplicar los ejemplos. Con lo cual se demuestra que no existe una ciencia puramente contemplativodesinteresada desligada de los procesos materiales y sociales. Desde los estudios de J.P. Vernant ${ }^{4}$ y de G. Thomson ${ }^{5}$ sabemos de la importancia que lo social, lo político y lo urbanístico, el espacio civil -el ágora- tuvo en las visiones cosmológicas.

En los textos de Aristóteles citados antes, el Estagirita ejemplifica su concepción de la filosofía mediante la referencia al "hombre libre". El hombre libre era, en Grecia, el ciudadano, polites: "Es, pues, evidente que no la buscamos por ninguna otra utilidad, sino que, así como llamamos hombre libre al que es para sí mismo y no para ningún otros, así consideramos a ésta como la única ciencia libre, pues ésta sólo es para sí misma". ${ }^{6}$

\footnotetext{
${ }^{3}$ Xavier Zubiri, Naturaleza, Historia, Dios, Editorial Nacional, Madrid, 1974, pp. 153-154.

${ }^{4}$ J.P., Vernant, Los orígenes del pensamiento griego, Eudeba, Buenos Aires, 1976.

${ }^{5}$ G. Thomson, Los primeros filósofos, Siglo XX, Buenos Aires, 1975.

${ }^{6}$ Aristóteles, Metafísica, A, 982a, 5/20.
} 


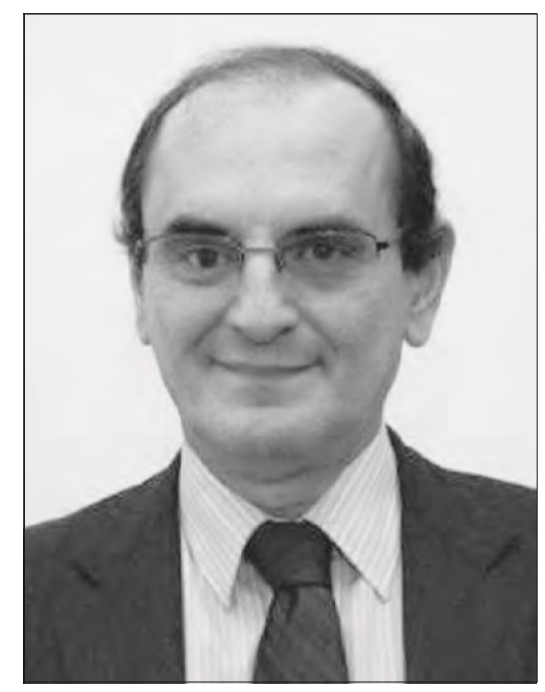

Héctor Samour

Los modelos socio-formos influyen en la ciencia y la filosofía; el modelo que influye en la concepción aristotélica de la filosofía es el del polítes. Y esto se ve con claridad si analizamos la teoría del sofós en Aristóteles. El ciudadano, polítes, era considerado libre, poseedor de un Estado soberano (polis), inteligente, racional, no esclavo, que mandaba sobre los demás. Son justamente las cualidades definitorias que Aristóteles estipula para el sabio y la sabiduría-filosofía. Por tanto, para comprender cómo surge la filosofía griega hay que entender y dar cuenta de los siguientes hechos: cómo estaba constituida la sociedad griega, así como los procesos y evoluciones de tal sociedad; qué significó y la importancia que tuvo la polis; cuáles eran las visiones que tuvo y el lenguaje que escribió el mito sobre la sociedad y la naturaleza; las influencias de la ciencia y las cosmovisiones orientales; el desarrollo de la lengua, y la influencia e importancia de las técnicas vinculadas al desarrollo de la producción de mercancías. Dar cuenta de estos puntos y de cómo ellos, más la genialidad de algunos autores, generaron una específica cosmovisión, es dar cuenta de la filosofía griega y, por ende, del origen de la filosofía occidental.

¿Por qué precisamente en Grecia hubo tales autores geniales (i.e. filósofos) y por qué aparece en Grecia, y no en otro lugar, la específica cosmovisión de ellos? ¿Por qué no aparece en otros pueblos? Los pueblos orientales habían alcanzado altas cotas de desarrollo de las ciencias, pero no aparecen tratados científicos teóricos ni surge la filosofía como modo de vida teorética en el sentido griego. La hipótesis que se sostiene ahora es que fue la organización políticosocial de los griegos, la polis, en el elemento decisivo en el surgimiento de la filosofía. ¿Por qué?

La polis implica libertad y contrastación de ideas; el logos de la polis patentiza la unidad de la diversidad, de la oposición de clases; las poleis de la Hélade adquieren 
su ser por reacción y en lucha contra la diferencia de los bárbaros (recordemos aquí las guerras contra los persas, las guerras médicas); la polis escribe un derecho que publica (las leyes de Solón); el ágora, centro de la polis, es el lugar de la concertación libre y de la expresión de la diferencia. La historiografía moderna ha reconocido la importancia de la polis y la influencia que tuvo en la manera de entender la vida, manera que propició la aparición de la ciencia y de la filosofía.

\begin{abstract}
"Las representaciones, por cuya virtud nacieron, entre otras, las ideas del derecho natural en Occidente, brotaron de aquellas formas más racionales de concepción antropomórfica del mundo que en la primera filosofía griega [...] reemplazaron al mito. Cuando las antiguas estructuras sociales, caracterizadas por la existencia de la nobleza rural, dejaron paso a la polis, las formas de vida urbana constituyeron el modelo de explicación del mundo. Por oposición a la arbitrariedad de esa nobleza constituida por los dioses olímpicos y a los impulsos irracionales de los demonios primitivos, el nuevo pensamiento está constituido y condicionado por el paradigma de una acción planificada y sistemática, normativamente regulada, propia del ciudadano en una actividad productiva especializada y en un ordenamiento comunitario riguroso". ${ }^{6}$
\end{abstract}

Sin la polis no se hubiera producido la filosofía griega. La filosofía es una ciencia para sí, libre, pública, que surge de la libertad que da el contraste y la discusión; estas son las características de la polis. Y por ello todo historiador de la filosofía griega ha de dar cuenta del hecho y esencia de la polis y de cómo ésta influye en el modo de pensar filosófico.

\title{
3. Interrelaciones mito-logos; el pensamiento mitológico versus no-mitológico
}

En la historia de la filosofía griega, mejor aún, en la cultura y civilización griegas, es difícil saber cuándo hay un pensamiento no mitológico. Algunos autores han sostenido que el pensamiento de los presocráticos es racional porque se ha apartado de un pensamiento anterior mítico-religioso; el viejo pensamiento mítico se caracterizaría por describir y explicar el mundo sin basarse en la observación ni en la contrastación; las explicaciones, descripciones del mito serían simbólicas, basadas en personificaciones divinas de las fuerzas de la naturaleza y que, por lo tanto, no se ajustarían a la realidad de lo sucedido. Pero tal forma de entender el pensamiento mítico y separarlo del experimentalista y/o racional no es, en modo alguno, convincente. Actualmente, a la luz de las últimas investigaciones sobre el mito en general, y sobre los mitos de los griegos en particular, la cuestión debe plantearse de otra manera.

\footnotetext{
${ }^{7}$ E. Topitsch, "El pensamiento mítico", en Kurt Lenk, El concepto de ideología, Amorrortu, Buenos Aires, 1974, pp. 75-83. 


\section{Samour, Héctor. La filosofía griega. Págs. 34-44. \\ DOI: http://dx.doi.org/10.5377/koot.v0i8.5867 \\ URI: http://hdl.handle.net/11298/382}

Es seguro que el pensar mitológico va asociado a un modo de pensar mágicoreligioso; es cierto que los presocráticos explican el mundo de forma muy diferente a como se explicaba, por ejemplo, en Homero; pero también es cierto que en los presocráticos hay una gran presencia de una forma de pensar y de decir fuertemente "personalizada": divinidades y conceptos divinizados aparecen, por ejemplo, en el poema de Parménides. Y la personalización es propia de un pensar mítico. También es cierto que los relatos míticos continuaron aún en la época de la sofística. Por ejemplo el mito de Prometeo narrado por Protágoras. Es claro que Protágoras utilizaba el ropaje del mito, o bien para prestigio literario-cultural de la tradición, o bien porque las gentes aún creían en él. Pero Platón retoma las narraciones míticas con más seriedad y no sólo como alegoría.

Los problemas son dos: uno, cómo era el modo de pensar mitológico de los griegos, y dos, cuándo se abandona ese modo de pensar y por qué. Aquí hay varios puntos de vista. J. Burnett sostiene que la filosofía de los presocráticos milesios es considerada como única, original y cualitativamente diferente de la producida por babilonios, egipcios o sus propios predecesores en Grecia, que habrían explicado la realidad mitológicamente. Esto lo lograron porque estaban dotados de la aptitud innata para realizarlo. ${ }^{7}$ Para Cornford, los griegos prearistotélicos no eran científicos porque no recurrían a la experimentación para controlar y ratificar sus especulaciones, presentando los primeros filósofos versiones más o menos racionalizadas de ancestrales ideas de Hesíodo, entre otros, y de las cosmologías de Babilonia, que a su vez hundían sus raíces en las estructuras totémicas originales de las tribus salvajes. Entonces la filosofía presocrática sería una reestructuración más racional y más sofisticada de los mitos tribales, que se diferenciaría sólo en la forma, pero no en el contenido. ${ }^{8}$

G. Thomson critica a Cornford, en el sentido de que éste expone el hecho de la racionalización que experimenta el pensamiento con el surgimiento de la filosofía de la naturaleza de los presocráticos, pero no lo explica adecuadamente a partir de la transformación y desarrollos inéditos que experimentaron las relaciones de producción, que barrieron las estructuras tribales y campesinas, base social del pensamiento mítico. Al cambiar las relaciones de producción se transformó la estructura de la sociedad, generando una distinta concepción del mundo. ${ }^{9}$

Para la escuela francesa (Gernet, Vernant y otros), el dato fundamental y el que marca la diferencia es el surgimiento de la polis. En vez de hablar de pensamiento mitológico versus pensamiento racional, hay que hablar de pensamiento pre-político (en el sentido etimológico de polis) y de pensamiento político. El pensamiento mítico sería un

\footnotetext{
${ }^{8}$ Cf. J. Burnett, La aurora del pensamiento griego, Argos, México, 1944. Traducción inglesa: Early Greek Philosophy, Londres, 1908.

${ }^{9}$ Cf. F. M. Cornford, From Religion to Philosophy: A Study in the Origins of Western Speculation, Princeton University Press, 1991.

${ }^{10} \mathrm{Cf}$. G. Thomson, Los primeros filósofos, op.cit. 
pensamiento pre-político en el sentido de ser el pensamiento de una sociedad fuertemente jerarquizada, característica principal de las sociedades monárquicas y aristocráticas, de base agraria, previas a la instauración de la polis en la Hélade, núcleo de la democracia. En sociedades de este tipo no puede haber filosofía en el sentido de teoría libre sobre los seres humanos y las cosas, sino fijos bloques ideológicos de interpretación sobre el mundo humanos y las cosas. A diferencia de la organización social en el despotismo oriental, la polis supone superación de formas tribales de vida; existencia de una legalidad consensuada, común, pública, asumida y aceptada por todos; una mezcla de lo cívico y lo religioso, es decir, mezcla de ágora y acrópolis; existencia de una legalidad que se constituye a partir de las diferencias de las distintas clases sociales; creación de un nuevo lenguaje; en el ágora se contrastan las diferentes opiniones y los distintos intereses; de la contrastación surge la voluntad de ser, la unidad en las diferencias.

¿Cuáles son las similitudes y diferencias entre la verdad mítica y la filosófica? En primer lugar, se diferencian en que la verdad mítica es asertórico-impuesta; se la cree sin contrastación, mientras que la verdad filosófica, ya desde el comienzo, se destaca por la contrastación y el debate; cada escuela filosófica, o cada filósofo, crítica o modifica doctrinas anteriores.

En segundo lugar, la verdad mítico-religiosa refleja el binomio autoridad-sumisión, en tanto que la filosófica se erige sobre la convivencia libre de los ciudadanos. Se diferencian también, en el tipo de lenguaje que utilizan: la verdad mítico-religiosa se acompaña de poesía, canto y ritos religiosos; posee la majestuosidad del poder, en tanto que la verdad filosófica se halla despojada de tales elementos. Es el paso de la poesía a la prosa. Este paso de la poesía a la prosa muestra claramente lo difícil que es el trazar una línea de separación radical entre mito y logos, pues personajes tradicionales considerados como filósofos, el caso de Heráclito y Parménides, usan un lenguaje poético-religioso y ritual, en gran medida. Con Heráclito y Parménides se observa precisamente el paso de un pensamiento mítico-religioso a otro plenamente no-religioso. ¿Por qué usan una forma religiosa, Heráclito en los tres primeros fragmentos de su libro, y Parménides en el Proemio de su poema?

Finalmente, la verdad mítico-religiosa era monolítica: ello no propiciaba investigaciones nuevas, porque era la reproducción laudatoria de los mismos eventos; es un desocultamiento de lo mismo; es una palabra de identidad; la reflexión filosófica, por el contrario, se introducía en la búsqueda de la diferencia o de la unidad de las diferencias.

Sin embargo, ambas verdades se asemejan en algunos aspectos. De algún modo, ambos tipos de verdad son un esfuerzo por arrancarse a la ocultación. Aletheia es un término negativo. A- es prefijo negativo que niega la raíz lethe, lo que está oculto. Aleteheia (verdad) significa desocultar, arrancar o arrancarse algo del olvido; salir algo a luz, mostrar o mostrarse algo. La physis se muestra, el ser se muestra mediante 
la palabra, el logos se muestra. En la sociedad y religión homéricas, y en otro tipo de religiones, como por ejemplo, las religiones mistéricas, la religión, que fundamentalmente era ritual, celebrando en sus misterios el de la naturaleza y el de la vida, propiciaba cultos, ritos, actos en que los sacerdotes recordaban, transmitían a la memoria la verdad oculta, aquello que los seres humanos tendían a olvidar. De manera semejante, la verdad filosófica era un desocultar, mediante la investigación y el razonamiento lógico, los misterios, las cosas ocultas de la naturaleza, la mente, el noetos y el comportamiento de los seres humanos.

Ambos tipos de verdad, y esto es lo importante, eran solidarios con su contexto: ambos fueron lo que tuvieron que ser: la verdad mítico-religiosa es el reflejo de una sociedad vertical, en tanto que la verdad filosófica es el reflejo de la diversidad contrastada libremente. No existe filosofía cuando la sociedad usa la cultura funcionalmente, esto es, acríticamente al servicio del poder que controla la sociedad, en tanto que hay filosofía cuando la reflexión crítico-comparativa genera la teoría. Y esto sucede cuando aparece la polis griega.

Esto se puede ver también a la luz del lenguaje. Se puede decir que la filosofía es el paso del káos al kósmos. Por ejemplo, la filosofía de Anaximandro sería una descripción del caos al cosmos. Pero, ¿qué significa kósmos? Significa orden. Entonces, la cosmología es el logos del cosmos, la descripción del orden. Antes del logro de la polis, el logos lo era de un kósmos dado, pero que ni era criticado ni puesto en cuestión: tal logos era, pues, una descripción narrativa y exaltadora, la cultura era un discurso de alabanza.

Cuando la polis adviene, se instaura un nuevo cosmos que, por su esencia, por ser más racional, es el kósmos por excelencia, el cual genera una nueva cultura. Kósmos es primariamente el orden de la polis y el orden de la cultura que esa polis genera. Desde el momento que la polis se logra, tal orden, que es humano, no divino, es perfectible. Tal kósmos posibilita un logos no descriptivo-narrativo, sino crítico-teórico.

La sociedad griega nos ha dado los siguientes conceptos básicos: orden (kósmos), ley (nomos), ágora, acrópolis, ciudadano (polítes), aerópago, lugar de la razón; y la cultura de tal sociedad acunó los siguientes conceptos: areté, virtud y perfección. Era virtuoso el ciudadano que seguía los ideales colectivos de la polis, por encima de los intereses de clase, el que defendía la ley de la polis; paideia, es decir, educación: el ciudadano era educado en tanto en cuanto asumía, se formaba en los ideales de polis, y contribuía con su crítica a la formación y al cumplimento de la ley.

\section{Interrelaciones sociedad-cultura-filosofía}

He estado explicando cómo surge la filosofía a partir de las correlaciones dinámicodialécticas entre sociedad-cultura-filosofía. Las variaciones culturales y filosóficas en 
función de la evolución de la institucionalidad político-social de la Hélade. Lo cual no significa un mero condicionamiento de abajo hacia arriba, sino también de arriba hacia abajo, es decir, de la cultura hacia la institucionalidad social y política. Se trata de una correlación estructural, y en la estructura, por definición hay co-determinación de los momentos que la configuran.

Pues bien, las evoluciones la institucionalidad político-social de la Hélade fueron a grandes rasgos, como sigue:

- La aristocracia fue la primera organización de las poleis. Y su cultura y su areté fueron correspondientes con ello. Poetas como Píndaro, los juegos olímpicos, la exaltación de la belleza masculina, etc., son algunas manifestaciones culturales de dicho período.

- Después advino la tiranía, con un una cultura isomórfica.

- Finalmente se generalizó la democracia en casi toda la Hélade.

Cada momento político generó un tipo de cultura, pero todos los momentos mencionados eran momentos o despliegue de la polis. Atenas, que fue la polis de mayor movilidad política, en la que se desarrollaron típicamente los momentos mencionados, fue la ciudad-estado en la que más ampliamente se desarrolló la filosofía. Antes de las guerras médicas, la filosofía floreció en las costas del Asia Menor, porque muchos de los "italianos" eran emigrados provenientes de las costas del Asia Menor.

Luego, la reflexión sobre los muchos modos políticos dio como resultado la filosofía de los sofistas. Posteriormente, constituidas ya las escuelas filosóficas, la nueva filosofía fue una respuesta a los problemas agonales de la filosofía anterior, pero estando la nueva filosofía condicionada por las nuevas situaciones sociales y culturales.

Tradicionalmente, la historia de la filosofía griega suele dividirse en presocráticos, Sócrates y los post-socráticos. Para algunos autores esta división les parece inadecuada, y proponen otras denominaciones alternativas. Así, por ejemplo, "antes y después de Parménides" o bien filosofía pre-sofística y post-sofística. Fue Cicerón quien escribió que Sócrates hizo bajar la filosofía del cielo a la tierra. Esa es la razón originaria de la división de la filosofía griega en presocráticos y post-socráticos. Lo que significa esa afirmación es que Sócrates habría dado a la filosofía una orientación antropológica, erigiendo al ser humano en modelo y norma del filosofar. Para algunos tal afirmación debe ser matizada. Sócrates sólo seguía -aun cuando aportase novedades y variaciones- los problemas plantados en su época, por los sofistas. Pero, por otro lado, el concepto filosófico por excelencia es el de "ser"; y dicho concepto lo acuñó Parménides. Y el reto de pensar el ser, lanzado por Parménides, es lo suficientemente importante para periodizar la historia de la filosofia griega en "antes y después de Parménides". 
En las postrimerías de la polis surgen filosofías de la añoranza, resumen del espíritu de la polis que se derrumbaba: así Aristóteles.

En la época de la sustitución de la polis por el imperio, por una nueva forma política que destruirá la eticidad lograda por la Hélade clásica, el desajuste individuo-Estado hará que surjan filosofías de la salvación individual: Así el epicureísmo.

\section{Referentes bibliográficos}

Alegre Gorri, Antonio, Historia de la filosofia antigua, Anthropos, Barcelona, 1988. Armstrong, A., Introducción a la filosofia antigua, EUDEBA, Buenos Aires, 1966. Bowra, C.M., La Atenas de Pericles, Alianza Editorial, Madrid, 1970.

Burnett, J., La aurora del pensamiento griego, Argos, México, 1944. Traducción inglesa: Early Greek Philosophy, Londres, 1908.

Cornford, F. M., From Religion to Philosophy: A Study in the Origins of Western Speculation, Princeton University Press, 1991.

Escohotado, A., De physis a polis: la evolución del pensamiento griego desde Tales a Sócrates, Barcelona, 1975.

Ferrer, Francisco, La filosofia presocrática, Universidad de Valencia, Valencia, España, 1978.

Gigon, Olof, Los orígenes de la filosofía griega: de Hesíodo a Parménides, Gredos, Madrid, 1968.

Guthrie, E., Los filósofos griegos, $8^{\mathrm{a}}$ edición, Fondo de Cultura Económica, México, 1982.

Thomson, G., Los primeros filósofos, Siglo XX, Buenos Aires, 1975.

Topitsch, E., "El pensamiento mítico", en Kurt Lenk, El concepto de ideología, Amorrortu, Buenos Aires, pp. 75-83. 1974.

Vernant, J. P., Los orígenes del pensamiento griego, Eudeba, Buenos Aires, 1976.

Zubiri, X., Naturaleza, Historia, Dios, Editorial Nacional, Madrid, 1974.

Zubiri, X., Los problemas fundamentales de la metafísica occidental, Alianza Editorial, Madrid, 1994. 


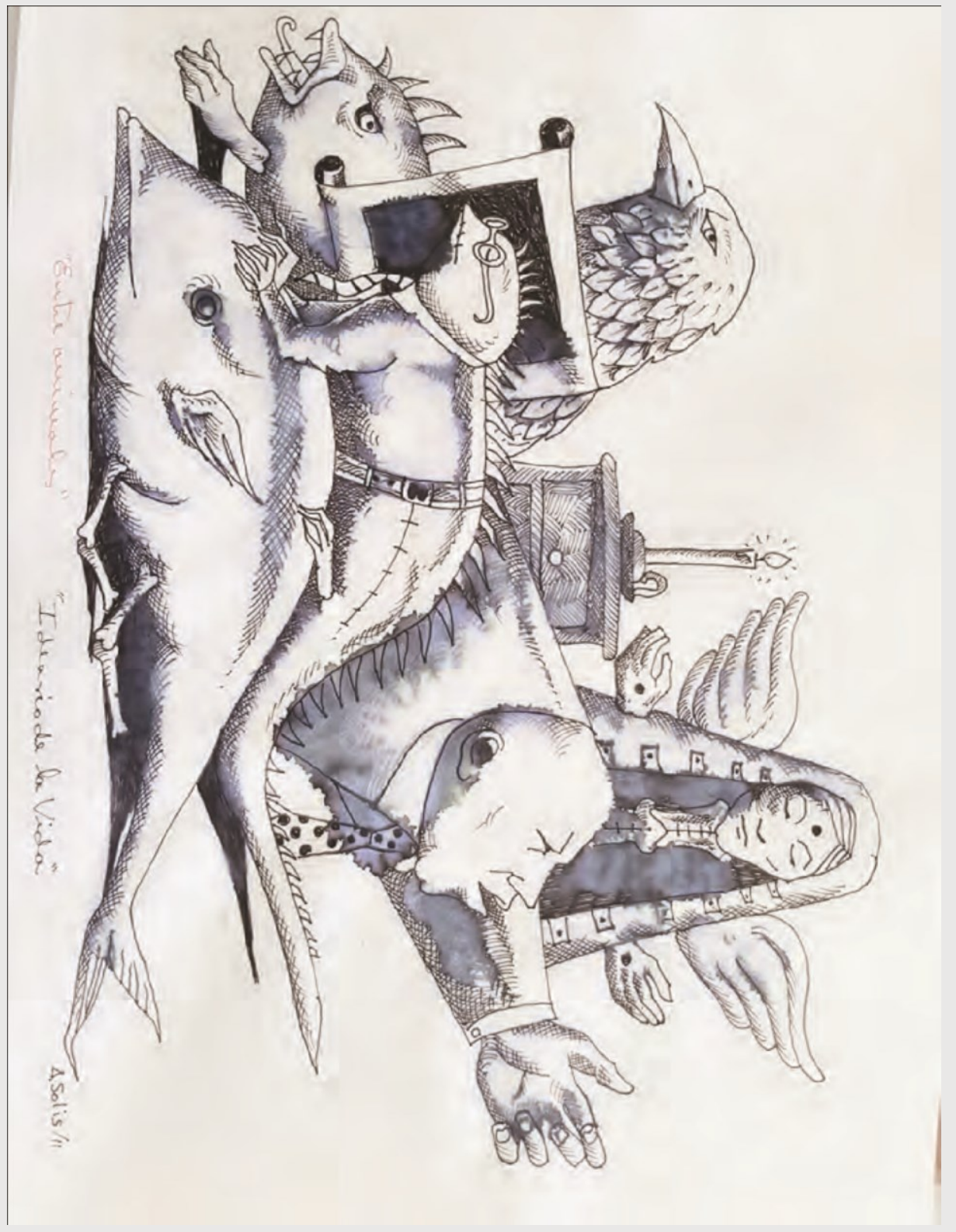

Armando Solis 